\title{
Genome wide transcriptome analysis reveals ABA mediated response in Arabidopsis during gold $\left(\mathrm{AuCl}_{4}^{-}\right)$ treatment
}

\author{
Devesh Shukla, Sneha Krishnamurthy and Shivendra V. Sahi*
}

Department of Biology, Western Kentucky University, Bowling Green, KY, USA

\section{Edited by:}

Georgina Hernandez, Centro de Ciencias Genómicas - Universidad Nacional Autónoma de México, Mexico

\section{Reviewed by:}

Daniel Pinero, Universidad Nacional Autónoma de México, Mexico Rajandeep Sekhon, Clemson University, USA

*Correspondence:

Shivendra V. Sahi, Department of Biology, Western Kentucky

University, 1906 College Heights, Bowling Green, KY 42101-1080, USA

e-mail: shiv.sahi@wku.edu
The unique physico-chemical properties of gold nanoparticles (AuNPs) find manifold applications in diagnostics, medicine and catalysis. Chemical synthesis produces reactive AuNPs and generates hazardous by-products. Alternatively, plants can be utilized to produce AuNPs in an eco-friendly manner. To better control the biosynthesis of AuNPs, we need to first understand the detailed molecular response induced by $\mathrm{AuCl}_{4}^{-}$In this study, we carried out global transcriptome analysis in root tissue of Arabidopsis grown for $12-\mathrm{h}$ in presence of gold solution $\left(\mathrm{HAuCl}_{4}\right)$ using the novel unbiased Affymetrix exon array. Transcriptomics analysis revealed differential regulation of a total of 704 genes and 4900 exons. Of these, 492 and 212 genes were up- and downregulated, respectively. The validation of the expressed key genes, such as glutathione-S-transferases, auxin responsive genes, cytochrome P450 82C2, methyl transferases, transducin (G protein beta subunit), ERF transcription factor, $A B C$, and MATE transporters, was carried out through quantitative RT-PCR. These key genes demonstrated specific induction under $\mathrm{AuCl}_{4}^{-}$treatment relative to other heavy metals, suggesting a unique plant-gold interaction. GO enrichment analysis reveals the upregulation of processes like oxidative stress, glutathione binding, metal binding, transport, and plant hormonal responses. Changes predicted in biochemical pathways indicated major modulation in glutathione mediated detoxification, flavones and derivatives, and plant hormone biosynthesis. Motif search analysis identified a highly significant enriched motif, ACGT, which is an abscisic acid responsive core element (ABRE), suggesting the possibility of $A B A$ - mediated signaling. Identification of abscisic acid response element (ABRE) points to the operation of a predominant signaling mechanism in response to $\mathrm{AuCl}_{4}^{-}$exposure. Overall, this study presents a useful picture of plant-gold interaction with an identification of candidate genes involved in nanogold synthesis.

Keywords: Au, microarray, Arabidopsis, glutathione, plant hormone, secondary metabolism, transporters, ABA responsive element (ABRE)

\section{INTRODUCTION}

Gold, one of the least reactive metal in periodic table, possesses unique properties, namely, high free electron density, malleability and conductivity, and favors opportunities to produce stable and tuneable AuNPs for potential applications in diagnostics, biological imaging, sensors, therapeutic agent delivery, photodynamic therapy, catalysis, electronics etc. (Chen et al., 2008; Yeh et al., 2012; Spivak et al., 2013). Many chemical methods have been developed for the synthesis of AuNPs, but they produce hazardous toxic by-products, posing serious environmental health issues (Limbach et al., 2007). Alternatively, plant-based systems of nanomaterial synthesis were established recently to produce a range of AuNP shapes and sizes (Kumar and Yadav, 2009; Starnes

Abbreviations: DEGs, Differentially expressed genes; $\mathrm{As}^{\mathrm{V}}$, Arsenate; $\mathrm{Cd}$ Cadmium et al., 2010; Geetha et al., 2013). Starnes et al. (2010) demonstrated in planta engineering of novel shapes in alfalfa by changing growth conditions of the plant. One of the current studies in Arabidopsis shows monodisperse spherical AuNPs formations in roots, grown hydroponically in the presence of $10 \mathrm{ppm}$ of $\mathrm{KAuCl}_{4}$ (Jain et al., 2014).

Metallic gold with zero nutritive value does not cause toxicity to living organisms but higher concentrations of gold solutions $\left(\mathrm{KAuCl}_{4}\right.$ or $\left.\mathrm{HAuCl}_{4}\right)$ may cause toxicity and impact plant growth negatively (Sharma et al., 2007; Starnes et al., 2010). Like other toxic heavy metals, for example, $\mathrm{Cd}, \mathrm{As}, \mathrm{Hg}, \mathrm{Pb}, \mathrm{Au}$ deactivates the proteins by binding to the sulfhydryl groups or disrupting the disulphide bonds and displacing the essential metal ion cofactors (Niemietz and Tyerman, 2002; Rodriguez et al., 2007).

A few investigations into the response of microorganisms to gold exposure have also been reported. For instance, Reith et al. (2009) characterized the mechanism of gold biomineralization in 
bacteria using a custom made microarray chip. Metal resistance genes, oxidative stress related genes and methyl transferases were reported to differentially express and cause reduction and detoxification of AuIII-complexes (Reith et al., 2009). Another interesting study demonstrated the involvement of a non-ribosomal small peptide - secreted as a secondary metabolite for the generation of solid gold particles from a gold resident bacterium Delftia acidovorans (Johnston et al., 2013).

Unlike the sufficient molecular information available with respect to heavy metals, little information is available in response to $\mathrm{AuCl}_{4}^{-}$exposure at whole transcriptome levels in plants (Taylor et al., 2014). Thus, the underlying mechanisms involved during the synthesis of AuNPs in plants remain largely elusive. To the best of our knowledge, the present study may be the first report of identifying the genes and mechanism operating in response to $\mathrm{AuCl}_{4}^{-}$treatment. This study will also help in predicting the changes in the associated metabolic networks.

In this study, 12 day old Arabidopsis root was exposed to chloroauric acid $\left(\mathrm{HAuCl}_{4}\right)$ for $12 \mathrm{~h}$, devoid of nutrient media, to record the specific response of $\mathrm{Au}$. The principal finding of this study demonstrates that Arabidopsis senses the gold treatment as a strong stimulus, modulating expression of a total of 704 genes, which account for $2.5 \%$ of the whole transcriptome. The ABAmediated signaling and glutathione binding appeared to be major possible mechanisms operating in response to $\mathrm{AuCl}_{4}^{-}$.

\section{MATERIALS AND METHODS PLANT MATERIAL, GROWTH CONDITIONS AND TREATMENTS}

Eighty seeds of the Arabidopsis thaliana cv. Col-0 were sterilized and germinated on mesh in each magenta box hydroponically in $0.5 \mathrm{X}$ MS medium for 5 days under a $16 \mathrm{~h}$ light $\left(120 \mu \mathrm{mol} \mathrm{m} \mathrm{m}^{-2}\right.$ $\left.\mathrm{s}^{-1}\right) / 8 \mathrm{~h}$ dark photoperiod at $23^{\circ} \mathrm{C}$ (Jain et al., 2009). Thereafter, these seeds were transferred into 1X MS medium and grown for 7 days (Jain et al., 2009). The 12 day old seedlings were transferred to a $10 \mathrm{ppm} \mathrm{AuCl}_{4}^{-}\left(\mathrm{HAuCl}_{4}\right.$, Sigma-Aldrich, USA) solution for $12 \mathrm{~h}$ at $\mathrm{pH} 4.2$, in absence of nutrient medium. Another set of parallel experiments for control were carried out with distilled water at $\mathrm{pH}$ 4.2. Care was taken to ensure that only the roots came in contact with the $10 \mathrm{ppm}$ gold solution. After $12 \mathrm{~h}$ of incubation in $\mathrm{AuCl}_{4}^{-}$, the roots and shoots were separately collected for further experiment. Similarly, the Arabidopsis seedlings were treated with $10 \mathrm{ppm} \mathrm{Ag}{ }^{+}\left[\mathrm{AgNO}_{3}\right.$; Acros, USA) $]$ and $10 \mathrm{ppm}$ $\mathrm{Cu}^{2+}\left[\mathrm{CuSO}_{4} .5 \mathrm{H}_{2} \mathrm{O}\right.$; Acros, USA $]$ and the root and shoot tissues were collected for further experiments. Three independent biological replicates were used for each treatment and around 240 seedlings were used in each biological replicate to isolate RNA.

\section{Total RNA isolation}

Total RNA was isolated from frozen root and shoot tissues separately using RNeasy Plant Mini Kit with on column DNase digestion (Qiagen, USA), according to the manufacturer's instructions. The integrity of RNA was checked on agarose gel and concentrations were determined using Nanodrop (Wilmington, DE, USA).

\section{TRANSCRIPTOME ANALYSIS}

Affymetrix GeneChip ${ }^{\circledR}$ ara ST 1.0 GeneChips (.cel files submitted to GEO, accession number GSE55436) were used to carry out the microarray experiment. Target preparation, hybridization to arrays, washing, staining, and scanning were carried out following the instructions of the manufacturer (Affymetrix, USA). Three independent biological experiments were carried out for control (no treatment) and experimental $\left(\mathrm{AuCl}_{4}^{-}\right.$treated) Arabidopsis seedlings. The hybridization data was processed using the Affymetrix GeneChip Command Console Software (AGCC version 3.2.4). Image files were analyzed to generate the probe intensity (.cel) files, using the default settings of AGCC. Microarray experiments were performed at the Microarray Core Facility of the University of Kentucky, in Lexington, Kentucky, USA. The probe set summarization (CHP) files for gene and exons were generated from feature intensity (.cel) files using RMA algorithms provided in the Expression Console v. 1.3. software. To identify statistically significant differentially expressed genes (DEGs) or exons, a combined criterion of greater than two-fold change was adopted with the ANOVA $p$-value (Condition unpair) $<0.05$ in the analysis. The normalized CHP files were analyzed using the secondary analysis tool Transcriptome Analysis Console, software to generate the.csv files containing DEGs.

\section{Identification of transcription factor}

The identification of transcription factors were carried out using a web based tool, a transcription factor database (http:// arabidopsis.med.ohio-state.edu/AtTFDB/). A separate list of transcription factors with their sub-family name and synonyms was prepared and listed in Table 2.

\section{GO enrichment analysis of DEGs}

The singular enrichment analysis (SEA, http://bioinfo.cau.edu. $\mathrm{cn} /$ agriGO/index.php) was carried out on up- and downregulated genes. The TAIR AGI IDs with their affiliated GO annotations were subjected to agriGO analysis using the customized annotation mode. Arabidopsis TAIR 10 database was used as a background. The hieratical graphs and GO enrichment analysis table of DEGs were prepared, using a hypergeometric test with Bonferroni correction, at $P$-value 0.05 , with 5 minimum number of mapping entries with complete GO gene ontology. The GO abundance chart was prepared manually by selecting the biologically relevant GO terms.

\section{Quantitative RT PCR validation of transcriptome}

The first strand cDNA was synthesized from $4 \mu \mathrm{g}$ of total RNA in $20 \mu \mathrm{l}$ reaction using Superscript III Reverse Transcriptase (Invitrogen Life Technologies, USA) using oligo $(\mathrm{dT})_{18}$ primers, according to the manufacturer's instructions. The prepared cDNA was diluted five times and $1 \mu \mathrm{l}$ (corresponding to $40 \mathrm{ng}$ total RNA) was used to perform quantitative RT-PCR (qRT-PCR) reactions using the SYBR Green (Applied Biosystem) on 7300 Real -Time PCR system (Applied Biosystems). The reaction conditions for PCR and dissociation curves were as follows: $95^{\circ} \mathrm{C}$ for $10 \mathrm{~min}, 40$ cycles of $95^{\circ} \mathrm{C}$ for $15 \mathrm{~s}, 58^{\circ} \mathrm{C}-60^{\circ} \mathrm{C}$ for $1 \mathrm{~min}$ and $95^{\circ} \mathrm{C}$ for $15 \mathrm{~s}, 60^{\circ} \mathrm{C}$ for $20 \mathrm{~s}, 95^{\circ} \mathrm{C}$ for $15 \mathrm{~s}, 60^{\circ} \mathrm{C}$ for $15 \mathrm{~s}$, respectively. To normalize the gene expression, beta tubulin was used as an endogenous control. Wherever possible, most of the primers were designed manually from $3^{\prime}$ UTR of the gene and verified using Oligo Analyzer-1.1.2. The primer sequences are listed in 
Supplementary Table S1. The qRT-PCR experiment was repeated two times independently and in each experiment, three technical replicates were used. Relative gene expression was calculated using the $2^{-\Delta \Delta C T}$ values following Livak's method (Livak and Schmittgen, 2001).

\section{Construction of heat map displaying expression profile of key genes under $\mathrm{AuCl}_{4}^{-}, \mathrm{As}^{\mathrm{V}}$, and $\mathrm{Cd}^{\prime \prime}$}

To differentiate the $\mathrm{AuCl}_{4}^{-}$specific response from toxic heavy metals, arsenate $\left(\mathrm{As}^{\mathrm{V}}\right)$ and cadmium $\left(\mathrm{Cd}^{\mathrm{II}}\right), 39$ genes, selected on the basis of their high expression level (>5-fold) under Au exposure as well as their availability with $\mathrm{Cd}$ and As experiment, were analyzed using the Genevestigator perturbation tool (https:// www.genevestigator.com/gv/plant.jsp). $\log (2)$-ratio change values of selected genes under $\mathrm{As}^{\mathrm{V}}$ and $\mathrm{Cd}^{\mathrm{II}}$ were obtained from Genevestigator program. A table was created by putting these values with the $\log (2)$-ratio values of $\mathrm{AuCl}_{4}^{-}$and a heat map was constructed using an online graphing tool, plotly (https://plot.ly/ plot). For the detail of the data please refer Supplementary File 4.

\section{Analysis of biochemical pathways}

The Plant MetGenMap, a web-based pathway analysis tool, was used to identify significantly changed biochemical pathways on the basis of expression profile data (http://bioinfo.bti.cornell.edu/ cgi-bin/MetGenMAP/home.cgi). An input text file was prepared by putting the TAIR AGI IDs, linear fold change value and $P$ value as per the instruction given in Plant MetGenMap. The file was uploaded as an individual project and analyzed, as per the instructions given in the manual.

Similarly, another text file was created according to the format prescribed in Plant Metabolic Network (http://pmn.plantcyc. org/overviewsWeb/celOv.shtml) and uploaded at the Omics Data Viewer under the analysis, sub-portal of the Plant Metabolic Network.

\section{Over-represented motif analysis in DEGs}

The upstream sequences (TAIR 10 Loci Seq-1000 bp) belonging to up- and down-regulated genes were downloaded using the Bulk Data Retrieval tool in a Fasta format and saved as a tab delimited text file format (http://www.arabidopsis. org/tools/bulk/sequences/index.jsp). The search was carried out using the web based Motif finder tool: SCOPE (http:// genie.dartmouth.edu/scope/). The parameters such as species, upstream sequence and strand search were selected as Arabidopsis thaliana, fixed $1000 \mathrm{bp}$ and plus and minus strands both, respectively. Additionally, the TAIR Motif analysis tool (http:// www.arabidopsis.org/tools/bulk/motiffinder/index.jsp) was also applied on the same data to further strengthen the results.

\section{RESULTS AND DISCUSSION GOLD EXPOSURE SIGNIFICANTLY MODULATES TRANSCRIPTOME}

In view of the rapid reduction of $\mathrm{Au}$ by sucrose or a nutrient ion like $\mathrm{Fe}^{2+}$, we believe, the use of a $\mathrm{HAuCl}_{4}$ solution devoid of nutrients would give us a precise insight into the interaction of plants with gold ions. Therefore, we isolated RNA from Arabidopsis plants exposed to 10 ppm gold solution at $\mathrm{pH} 4.2$ (the natural $\mathrm{pH}$ of a gold solution) and microarray was performed using new unbiased Ara ST 1.0 chip on Affymetrix platform. After normalizing the image files using the RMA algorithm, principal component analysis revealed a distinct position of $\mathrm{AuCl}_{4}^{-}$treated samples from the control, suggesting a significant change in the transcriptome (Figure 1A). The microarray data was submitted to Gene Expression Omnibus (NCBI), with accession no. GSE55436. A One-Way ANOVA model was applied to the intensity data with adopted criterion: $>2$-fold change turning into a statistically significant $(\mathrm{FDR} \leq 0.16)$ list of 704 genes $(2.5 \%)$ and 4900 exons $(2.8 \%)$ (Figure 1B, Table 1, Supplementary File 1). The high percentage of differentially regulated exons indicated occurrence of a number of alternative splicing events opening the opportunity to study it further (Supplementary File 2). The number of

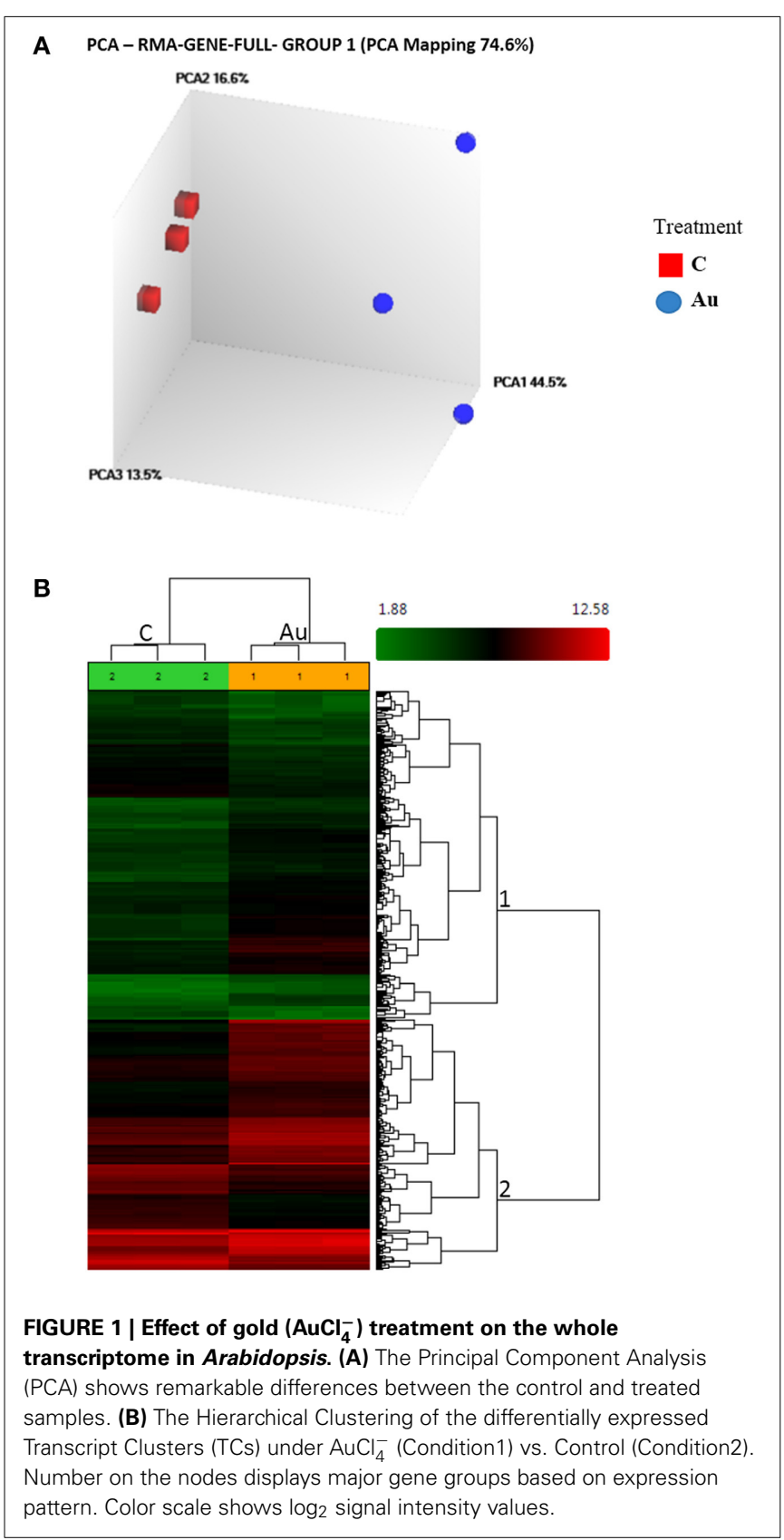


Table 1 | Summary of transcriptome analysis.

\begin{tabular}{|c|c|c|c|}
\hline S. No. & Query type & Genes & Exons \\
\hline 1 & Analysis type & $\begin{array}{l}\text { Gene level differential expression } \\
\text { analysis }\end{array}$ & $\begin{array}{l}\text { Exon level differential expression } \\
\text { analysis }\end{array}$ \\
\hline 2 & Array Type & \multicolumn{2}{|c|}{ AraGene-1_0-st } \\
\hline 3 & Genome version & \multicolumn{2}{|c|}{ tair10 } \\
\hline 4 & Annotation file & $\begin{array}{l}\text { aragene-1_0-st- } \\
\text { v1.na33.3.tair10.transcript.csv }\end{array}$ & $\begin{array}{l}\text { aragene-1_0-st- } \\
\text { v1.na33.3.tair10.transcript.csv } \\
\text { aragene1_0-st- } \\
\text { v1.na33.2.tair10.probeset.csv }\end{array}$ \\
\hline 5 & Total number & 28403 & 171941 \\
\hline 6 & Differentially expressed & 704 & 4900 \\
\hline 7 & Up regulated (Exp. Vs. Con) & 492 & 2690 \\
\hline 8 & Down regulated (Exp. Vs. Con) & 212 & 2210 \\
\hline 9 & Algorithm & \multicolumn{2}{|c|}{ One-Way between-subject ANOVA (unpaired) } \\
\hline 10 & Default filter criteria 1 & \multicolumn{2}{|c|}{ Fold change (linear) $<-2$ or fold change (linear) $>2$} \\
\hline 11 & Default filter criteria 2 & \multicolumn{2}{|c|}{ ANOVA $p$-value (condition pair) $<0.05$} \\
\hline
\end{tabular}

upregulated genes (nos. 492) observed were more than double of the number of downregulated genes (nos. 212), indicating the suitability of the exposed concentration (Table 1, Supplementary File 1).

\section{GENERAL ANNOTATION OF DEGs IN RESPONSE TO AuCl-}

We described the functional roles of genes that shared a similar family and/or category on the basis of available literature and annotations. Glutathione-S-transferases (GSTs) were the major detoxifying enzymes that catalyze the conjugation of reduced glutathione to different cytotoxic substrates and subsequently transport into the vacuole in an ATP-dependent manner. These genes are induced by a number of metabolic processes, as well as in response to stress, heavy metals or plant hormones (auxin/jasmonic acid) (Mars, 1996; Chakrabarty et al., 2009). Additionally, some GSTs also showed glutathione peroxidase activity, strengthening their role in antioxidant metabolism (Mars, 1996). Nineteen members belonging to the GSTs family were differentially regulated (Supplementary File 1). Most of the members belong to GST-tau and GST-phi, GST-lambda class (Wagner et al., 2002). These proteins were classified under multiple GO categories, for example, metabolic process, cellular process, response to stimulus or stress or biotic stimulus, secondary metabolic process, catabolic process and lipid metabolic process (Supplementary File 3). Members of Phi class, were reported to show Co or $\mathrm{Cu}$ ion binding activity (Supplementary File 3). An important member of GST phi class, AT1G49860 (GSTF14), was found to be downregulated by 4.4 -fold, and involved in anion transport, lateral root development, and root hair cell differentiation (Supplementary File 1). Altogether, these observations suggest a possibility of GSH-based detoxification and reduction of ionic Au species into 0 valent non-ionic, non-reactive form.

Seven members of beta-glucosidase gene family were upregulated at varying levels (Supplementary File 1). The expression patterns of these classes of genes were reported to alter according to the change in the level of sugar inside the cell (Lee et al., 2007). The beta-glucosidase 30 was expressed at the highest level (26-fold) and known for hydrolysing o-glycosyl compounds and modified cell walls (Fujiki et al., 2001). Additionally, deglucosylating activities of these enzymes may regulate the activity of a glucosylated forms of a plant hormone. Three other sugar transporters, members of the ERD6 family, were downregulated (Supplementary File 1). These observations suggest that the gold $\left(\mathrm{AuCl}_{4}^{-}\right)$exposure could change the level of sugar inside the cell, triggering sugar associated signaling.

Cytochrome P450 is a stress responsive super gene family, comprising 267 members in Arabidopsis, and plays a variety of roles in biological processes like oxidation-reduction and detoxification of xenobiotics (Chakrabarty et al., 2009; Liu et al., 2010). These proteins share a class under metabolic, cellular process and response to stress or stimulus. Twenty members of this family were differentially regulated, in which 13 were up- and 7 were downregulated (Supplementary File 1). The highest expression was 22.7-fold for cytochrome P450, family 82, subfamily C, polypeptide2 (AT4G31970), which was known to induce under hypoxia condition and shows jasmonate-induced root growth inhibition, electron carrier, oxido-reductase and oxygen binding activity (Liu et al., 2010).

Four auxin response related genes were upregulated, signifying $\mathrm{AuCl}_{4}^{-}$-induced auxin signaling (Supplementary File 1). AT1G60750 locus encodes an auxin-induced atb2-like protein involved in metabolic processes such as oxidation and reduction. AT5G13370, an auxin responsive GH3 family protein, was reported to induce in response to auxin stimulus (Takase et al., 2003). AT1G76520, an auxin efflux carrier protein, possesses auxin-hydrogen symporter activity and is involved in auxin polar transport and localization (Barbez et al., 2012). Recently, in one of our studies we showed the progressive reduction of primary root length and meristematic activity of primary and lateral roots under higher concentrations of $\mathrm{AuCl}_{4}^{-}$(Jain et al., 2014). Overall, the upregulation of these genes suggest the importance of $\mathrm{AuCl}_{4}^{-}$ mediated-auxin response, which has the capacity to modulate the root system architecture (Jain et al., 2014).

Fourteen different methyl transferases (MTs) were differentially regulated. Six members of S-adenosyl methionine 
(SAM) -dependent MTs, two members of O-methyl-transferase protein and two others were upregulated (Supplementary File 1). SAM is a well-known methyl donor, suggesting the significance of the methylation event in response to gold. These results are in agreement with an earlier study in which a microorganism exposed to $\mathrm{AuCl}_{4}^{-}$exhibited upregulation of several MTs, suggesting the possibility of Au methylation as a conserved detoxification mechanism (Reith et al., 2009).

Three members of ABC transporter G family were upregulated (Supplementary File 1). One member, PDR12, was reported to be induced in response to auxin, ABA, ethylene, cyclopentenone, jasmonic, and salicylic acid (Lee et al., 2005; Kang et al., 2010). Additionally, it was known to take part in transportation of $\mathrm{Pb}, \mathrm{ABA}$, and terpenoids, revealing some new possibilities with respect to $\mathrm{AuCl}_{4}^{-}$transport (Lee et al., 2005; Kang et al., 2010).

A large gene family of at least 56 members encoding MATErelated proteins was identified from the Arabidopsis genome (Tiwari et al., 2014). MATE are known to play various roles, such as disease resistance, trafficking of secondary metabolites into the vacuole, and exporting out the small organic molecules like citric acid to sequester metal ions or iron transport and distribution in the plants (Tiwari et al., 2014). In the present study, five members of the MATE gene family were upregulated (Supplementary File 1). Of these, an important gene, ATDTX1, was earlier identified as a detoxifying efflux carrier exporting toxic compounds outside the cell (Li et al., 2002).

Sulfate transporters are shown to be induced under sulfur starvation, as well as against the exposure of heavy metals (Chakrabarty et al., 2009). Sulfur is the vital part of S-rich nonprotein thiols like GSH and phytochelatins, known to exhibit heavy metal tolerance and accumulation (Shukla et al., 2012, $2013 a, b)$. Interestingly, the expression of two members of the phytochelatin synthase (PCS) gene family was modulated $<2$-fold in the present study, indicating the role of PCs in the detoxification of $\mathrm{Au}$ (data not shown). In this case, sulfate transporter 3.1 encoding a chloroplast localized transmembrane protein was also upregulated by 6.5 -fold (Supplementary File 1), similar to that reported by Cao et al. (2013). Another member, sulfate transporter 3.5 was upregulated by 4.8 -fold and known to be involved in root to shoot transport of sulfates. Induction of these transporters may suggest the enhanced requirement of S-containing non-protein thiols against the oxidative stress caused by $\mathrm{AuCl}_{4}^{-}$ exposure.

A phosphate transporter 3.2, which encodes a mitochondrial phosphate transporter 2 (MPT2), reported to be induced in response to ethylene stimulus, was upregulated (Supplementary File 1). Nodulin, a group of MTN21-like transporter family proteins involved in the transport of multiple amino acids, were upregulated (Supplementary File 1). Similarly, a transmembrane amino acid transporter, (AT1G08230), which codes for an $\mathrm{H}^{+}$driven, high affinity gamma-aminobutyric acid (GABA) transporter localized at plasma membrane, was upregulated (Supplementary File 1). Some putative oligo-peptide transporters (OPTs), known for the transport of peptides/nitrates having the probability of metal binding, were upregulated (Supplementary File 1). Interestingly, two heavy metal associated domain containing transporters, were also up- and downregulated. It appears that the treatment of gold $\mathrm{Au}$ ) also upregulated some transporters, which are relatively new or less characterized.

\section{IDENTIFICATION OF TRANSCRIPTION FACTORS FROM DEGs}

In order to shed light on the regulatory genes modulated by the $\mathrm{AuCl}_{4}^{-}$treatment, we separated the list of transcription factors from DEGs using an Arabidopsis transcription factor identification web-based tool (http://arabidopsis.med.ohio-state.edu/ AtTFDB/). We found a total of 57 transcription factors that were differentially expressed in the present experiment (Table 2 ). The high number of expressed regulatory proteins in this experiment indicates their important role in transcriptome modulation. Of these, the maximum number (10) was represented by the members of AP2 domain containing ethylene-responsive element binding proteins (AP2-EREBP) and NAC domain containing proteins. Generally, the AP2EREBP gene family was known to be involved in plant responses to drought, cold, salt, and ABA signaling (Mishra et al., 2013, 2014). Interestingly, a member of the AP2-EREBP family (At5g64750), was reported to induce by ABA treatment but functions as a transcriptional repressor of ABA response (Pandey et al., 2005). Members of the NAC gene family were reported to associate with plant senescence (Shibuya et al., 2014). Recently, Christiansen and Gregersen (2014) showed that the NAC TF binds with the CGT motif. It is worth stating that CGT motif shares a part with the abscisic acid responsive core element (ABRE), ACGT. Six members of the R2R3-MYBs gene family were differentially expressed in Arabidopsis; these are known to be involved in abiotic stress response. Five members of the WRKY gene family were differentially regulated as well, of which WRKY70 and WRKY63 were earlier reported to be involved negatively in leaf senescence and ABA response, respectively (Ren et al., 2010; Besseau et al., 2012). WRKY8, and WRKY31 were reported to be involved in jasmonate signaling (Schluttenhofer et al., 2014). WRKY28 is responsive to drought, salt, and oxidative stress (Tripathi et al., 2014). Some other members of different regulatory gene families were also expressed, such as $\mathrm{C} 2 \mathrm{H} 2$ zinc-finger, Homeobox HDZIP, bHLH, $\mathrm{C} 3 \mathrm{H}$, Trihelix, C2C2-CO-like and GRAS etc. Overall, a common signaling event associated with these regulatory proteins is senescence. Hence, it may be possible that abscisic acid (ABA) is playing a key role in mediating plant responses against the $\mathrm{AuCl}_{4}^{-}$challenge.

\section{SINGULAR ENRICHMENT ANALYSIS (SEA) OF DEGs}

To discern the relevant biological meaning, SEA was performed on the DEGs using an AgriGO analysis tool (Supplementary File 3). Seventy-nine significantly (FDR < 0.04) enriched GO terms were grouped under three functional categories: biological process (BP); cellular component (CC); and molecular function (MF) (Supplementary Figure 1). Of these, 23 GO terms, which were biologically relevant with the present experiment and objective, were displayed in Figure 2. The response of plant hormones, such as cyclopentenone, an intermediate of jasmonic acid, ethylene, and abscisic acid, appears to be upregulated. The ABA associated response, oxidative stress, metal ion binding, transport and glutathione binding were also found to be upregulated. This data suggest that $\mathrm{AuCl}_{4}^{-}$treatment may trigger ABA specific 
Table 2 | List of transcription factors regulated during $\mathrm{AuCl}_{4}^{-}$treatment.

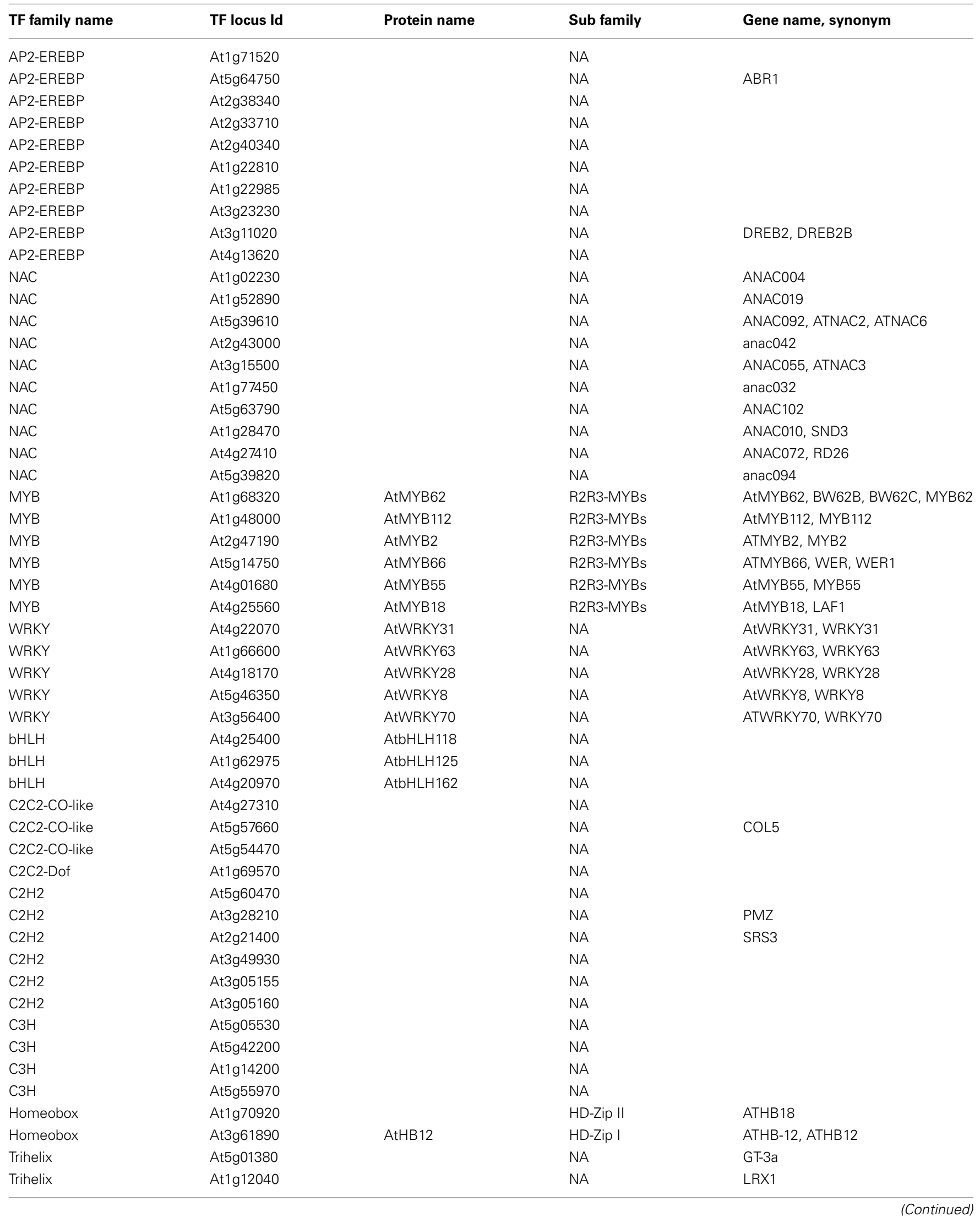


Table 2 | Continued

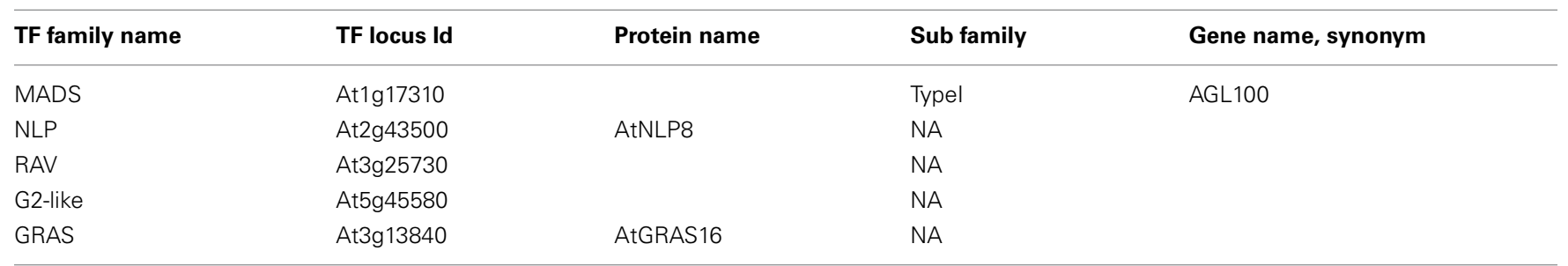

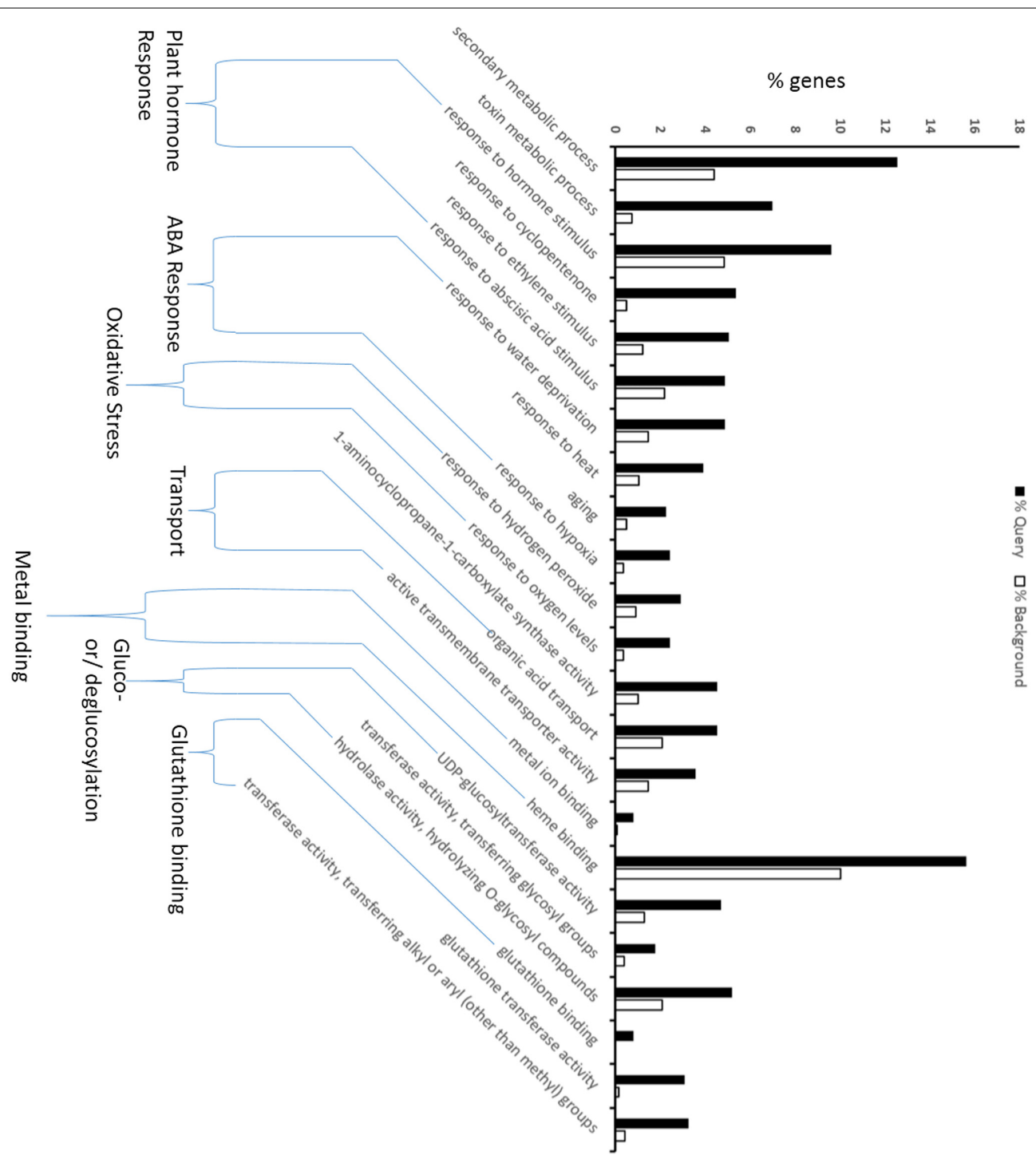

FIGURE 2 | GO enrichment analysis for differentially regulated genes during gold treatment $\left(\mathrm{AuCl}_{4}^{-}\right)$. The analysis shows the ABA and Glutathione related processes were affected. The Singular Enrichment Analysis (SEA) of up- and downregulated genes with their GO IDs was performed using the agriGO analysis tool under customized mode,
$P<0.05$ and minimum 5 mapping entries. The black bar shows the fraction of query genes for particular GO term out of total no. of query genes, and the white bar provides the similar information with respect to genes present in background (whole genome). Please see details in Materials and Methods. response, which could potentially modulate the expression of large set of genes. Water deprivation, heat, hypoxia and aging are associated with the ABA-mediated signaling, strengthening the ABA specific response. Moreover, ethylene and ABA do cross talk with each other at several points and together may generate these responses. Toxicity of gold solution may produce oxidative stress similar to other toxic heavy metals, and upregulation of $\mathrm{H}_{2} \mathrm{O}_{2}$ response is a sign of oxidative stress. The plant produces 
non-enzymatic antioxidant molecules such as GSH, ascorbic acid and secondary metabolites to combat the oxidative stress. In this study, glutathione appeared to be a key player for reducing the oxidative stress. A significant upregulation of GST activity opens the possibility of conjugation of GSH with toxic metabolites like ROS, or possibly $\mathrm{AuCl}_{4}^{-}$, to sequester them into the vacuole for detoxification (Figure 2).

\section{COMPARATIVE EXPRESSION PROFILE OF KEY GENES UNDER AUCI- AND TOXIC HEAVY METAL}

The effect of $\mathrm{AuCl}_{4}^{-}$on plant gene expression is largely elusive, however, the research on plant-based synthesis of Au nanoparticles has started to show results. In order to differentiate the $\mathrm{AuCl}_{4}^{-}$specific genetic response from toxic heavy metal(loid)s like arsenic (As) and cadmium (Cd), we constructed a heat map by taking 39 genes on the basis of high expression cut off ( $>5$-fold) under $\mathrm{AuCl}_{4}^{-}$exposure as well as their presence under $\mathrm{Cd}$ and As exposure (Supplementary File 4). In general, all these genes were highly upregulated in the presence of $\mathrm{AuCl}_{4}^{-}$. Contrastingly, they were found to be downregulated in presence of $\mathrm{As}^{\mathrm{V}}$ or $\mathrm{Cd}^{\mathrm{II}}$ (Figure 3). These genes showed a significantly distinct expression profile in the presence of $\mathrm{AuCl}_{4}^{-}$, compared to $\mathrm{As}^{\mathrm{V}}$ and $\mathrm{Cd}^{\mathrm{II}}$, suggesting that the interaction of $\mathrm{AuCl}_{4}^{-}$with plants is different. Since $\mathrm{Au}$ ions or nanoparticles possess distinct-physicochemical properties, it may generate a unique signature on the plant transcriptome.

\section{VALIDATION OF ARRAY DATA USING qRT-PCR UNDER AuCl- ${ }_{4}^{-}$, AS WELL AS FOR Ag AND Cu EXPOSURE}

Twelve key genes, were selected on the basis of their possible role in $\mathrm{Au}$ - reduction, detoxification, plant hormone responses, signaling, transport, transcriptional regulation and unknown function for the validation of microarray data through quantitative RT-PCR (Figure 4). We performed the qRT-PCR separately for the root and shoot tissues to resolve tissue-specificity. Including $\mathrm{Au}$, we chose metals sharing similar group in the periodic table (i.e., Ag, $\mathrm{Cu}$ ) to test the metal specificity. The quantitative gene expression results correlated with the trend of regulation observed in the microarray experiment. In general, the expression level of genes was higher in root as compared to shoot (Figure 4). The transporters (PDR-12, MATE), and GSTs were more responsive to $\mathrm{AuCl}_{4}^{-}$, compared to $\mathrm{Ag}$ and $\mathrm{Cu}$, indicating probably their role in $\mathrm{Au}$ reduction or detoxification (Figure 4). Cytochrome P450 (AT4g31970, CYP82C2) was upregulated significantly in response to $\mathrm{AuCl}_{4}^{-}$, indicating their involvement in detoxification (Figure 4). This enzyme possesses properties like oxidoreductase activity, acting on paired donors, with incorporation or reduction of molecular oxygen (Supplementary File 3). Expression of an auxin efflux carrier (AT1G76520) suggests the triggering of auxin mediated signaling. Expression of ethylene biosynthesis and signaling related genes: ACS2 (AT1G01480) and ERF20 (AT1G71520) points toward the Au-mediated induction of ethylene and ABA signal transduction (Figure 4). Surprisingly, a beta subunit of G protein, named here as transducin (AT1G18830), was upregulated in response to $\mathrm{AuCl}_{4}^{-}, \mathrm{Ag}$ and $\mathrm{Cu}$ in a decreasing order (Figure 4). G protein coupled receptors are known to be involved in $\mathrm{ABA}$ reception (Nitta et al., in press). It can be hypothesized that the plant uses an ABA receptor, associated with $G$ protein, and transduces signaling, modulating the expression of a large set of genes for adaptation purpose under $\mathrm{AuCl}_{4}^{-}$exposure (Yadav et al., 2013, 2014).

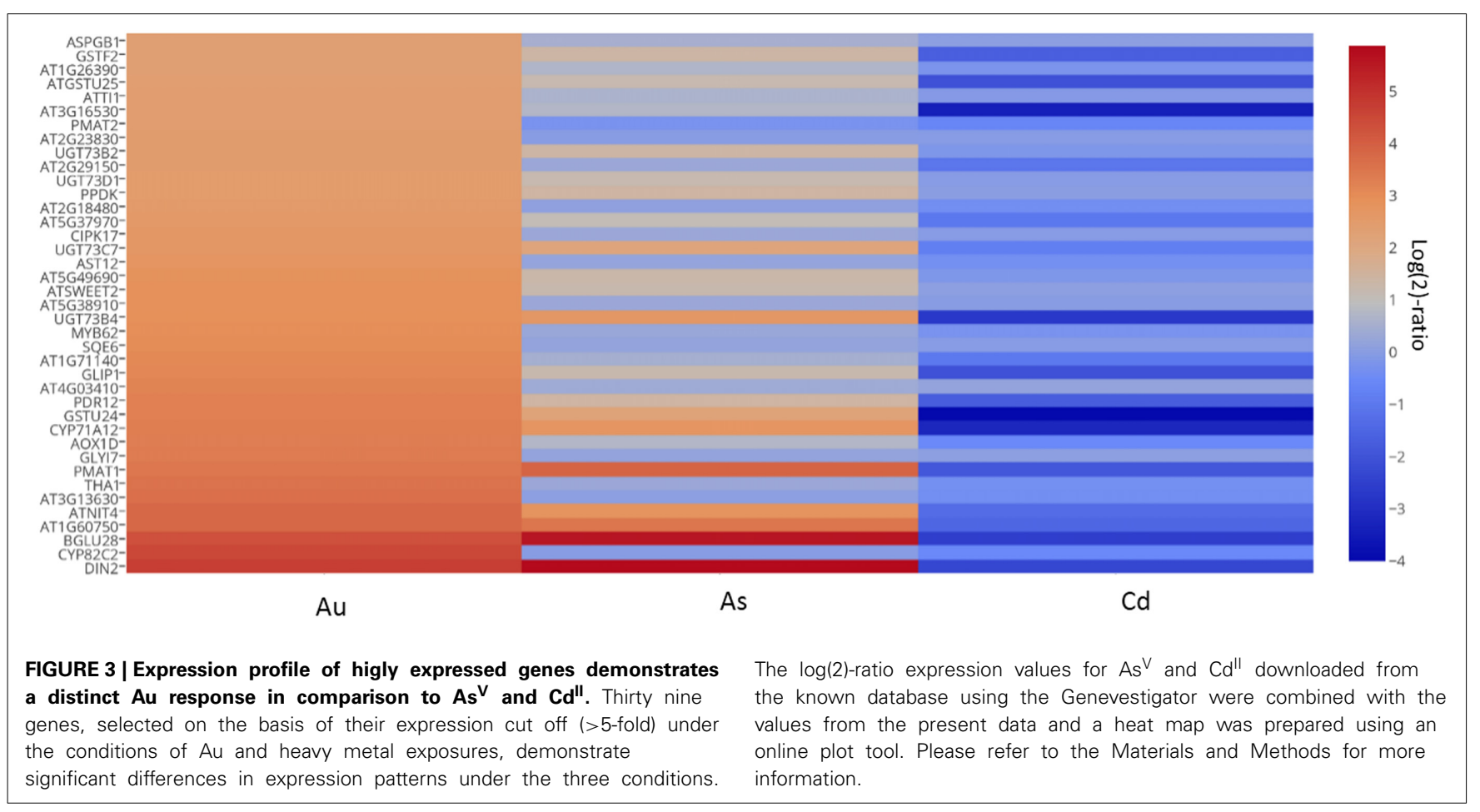



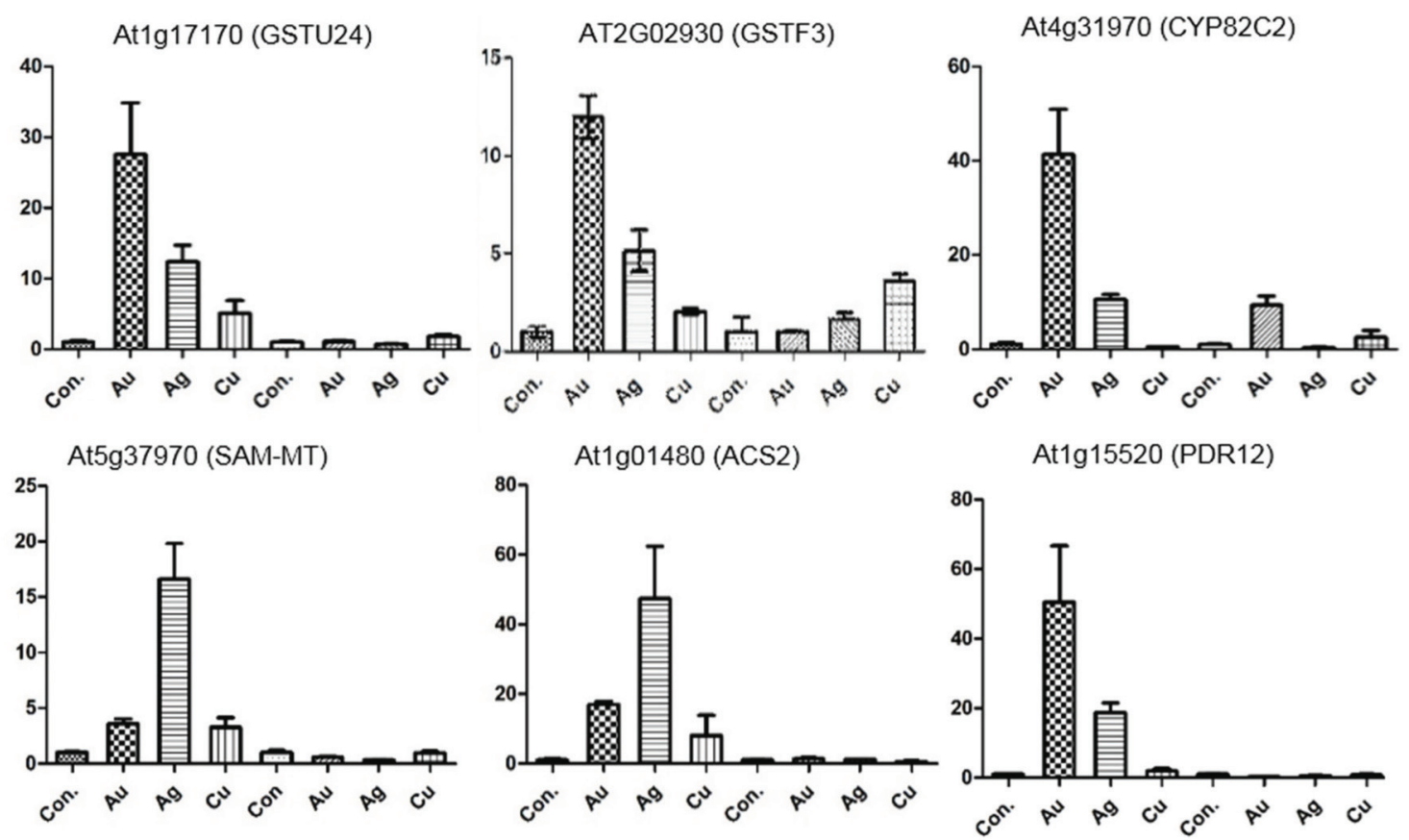

At1g15520 (PDR12)

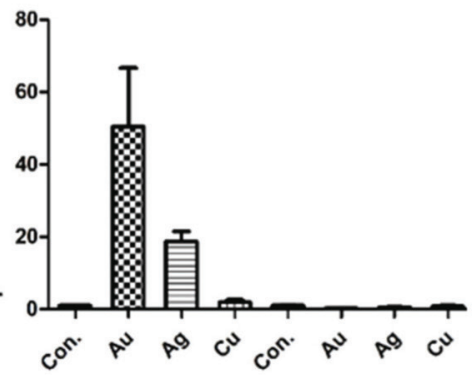

At1g18830 (Transducin)
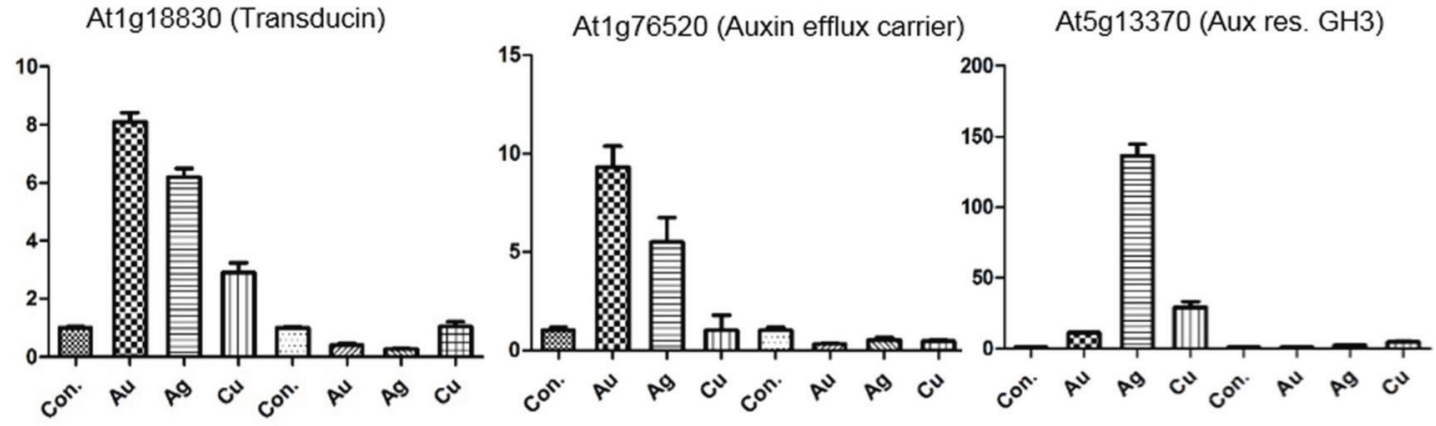

At1g71520 (ERF20)
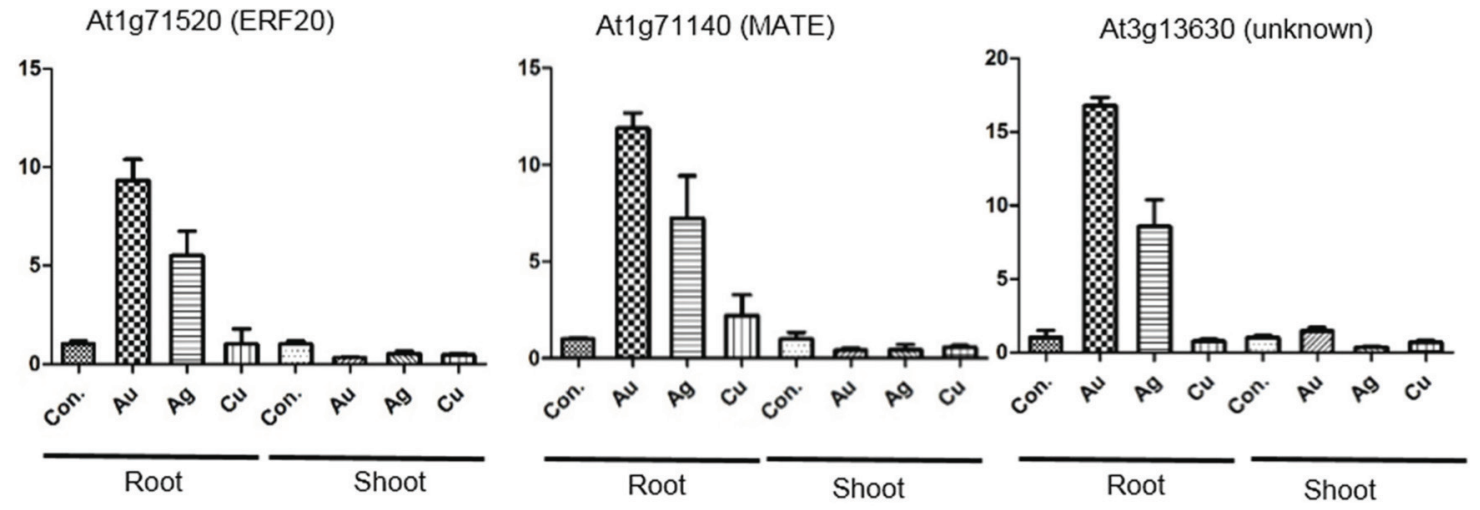

FIGURE 4 | Validation of the array data through qRT-PCR. The expression analysis of the selected genes shows the positive correlation with the microarray data. qRT-PCR was carried out with

PREDICTION OF PLANT METABOLIC SHIFT IN RESPONSE TO AuCl-

To visualize the effect of $\mathrm{AuCl}_{4}^{-}$in the context of metabolic pathways, we analyzed the DEGs using web-based analysis program, Plant MetGenMap (http://bioinfo.bti.cornell.edu/ root and shoot tissues of Arabidopsis exposed to $\mathrm{AuCl}_{4}^{-}, \mathrm{Ag}^{+}$, and $\mathrm{Cu}^{2+}$, under similar experimental conditions used for the microarray analysis.

cgi-bin/MetGenMAP/home.cgi) and Plant Metabolic Network (http://pmn.plantcyc.org). Glutathione mediated detoxification, flavones and derivative biosynthetic, ethylene biosynthetic, cytokinins-O-glucoside biosynthetic, jasmonic acid biosynthetic, 


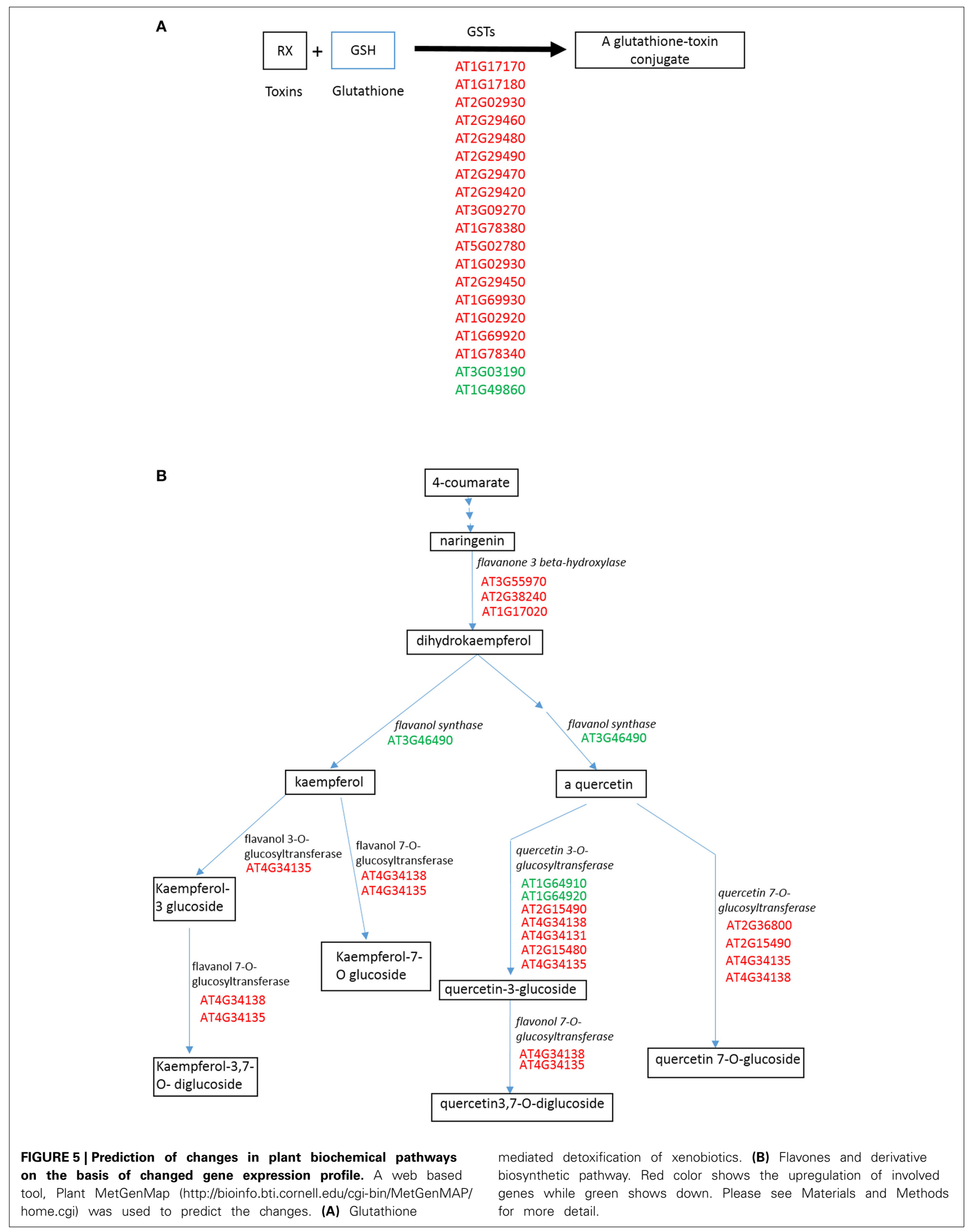


and terpenoids pathways were predicted to be significantly changed (Figure 5, Supplementary Figures 2, 3, Supplementary File 5). It appears that the glutathione conjugation was used as a primary tool to cope up with toxicity. Flavones and derivative biosynthetic pathways were predicted to be upregulated. Upregulation of glucosyltransferases indicates the glucosylation of compounds, which could change the biological activity significantly. Flavones like quercetin and Kaempferol possess antioxidative properties, thus they might reduce the stress effects (WinkelShirley, 2002). We predicted glucosylation of cytokinins leading to the inhibition of cytokinin activity (Supplementary Figure 2), as in an earlier study (Hou et al., 2004). Similarly ABA was predicted to be conjugated with glucose, turning it into an inactive form (Supplementary Figure 2). These modifications are often required to maintain a fine tuned equilibrium between active and inactive forms of the plant hormones. Interestingly, lutein (terpenoids) biosynthesis was also predicted to be upregulated. It is reported to have unique medicinal properties and used as an antioxidant (Tian et al., 2004). Overall, these biochemical predictions indicate a fine-tuned regulation of secondary metabolites to address the challenge posed by the $\mathrm{AuCl}_{4}^{-}$treatment.

\section{IDENTIFICATION OF OVER-REPRESENTED MOTIFS IN UPSTREAM SEOUENCES OF DEGs IN RESPONSE TO AuCl-}

The question of identification of over-represented cis-regulatory elements is important as it sheds light on the regulatory mechanism active in the particular environmental condition. To address this, we pulled out the $1000 \mathrm{bp}$ upstream sequences of the upor downregulated genes from the Tair 10 database and submitted them to the SCOPE motif finder tool (http://genie.dartmouth. edu/scope/) to identify the enriched motifs. We identified an abscisic acid response core element, (ABRE): ACGT, in the 1000 bp upstream sequences of 419 upregulated genes (Table 3, Figure 6). The same motif was also identified by the TAIR motif finder tool (http://www.arabidopsis.org/tools/bulk/motiffinder/ index.jsp, data not shown). Interestingly, the top two statistically significant motifs represented ABRE cis-regulatory elements (Figure 6). Table 3 describes the general information about the motif. For example, count indicates the number of occurrence of the motif in the input data. Coverage indicates the fraction of genes containing the motif, and the algorithm used to identify the motif.

ABA, known as an abiotic stress hormone of plants, mediates several signaling reactions in response to altered environmental conditions. The motif ACGT was earlier identified in the regulatory regions of the genes induced by environmental related

Table 3 | Summary features of 5 most significant motifs enriched by the SCOPE tool.

\begin{tabular}{lcccc}
\hline $\begin{array}{l}\text { Consensus } \\
\text { sequence }\end{array}$ & Count & $\begin{array}{c}\text { Sig } \\
\text { value }\end{array}$ & $\begin{array}{c}\text { Coverage } \\
\text { (\%) }\end{array}$ & Algorithm \\
\hline Acgtnd & 2191 & 200.2 & 94.3 & PRISM \\
Acgtg & 656 & 73.6 & 69.3 & PRISM \\
Rktcwahv & 840 & 55.0 & 88.9 & PRISM \\
Aatat & 3378 & 51.3 & 98.8 & PRISM \\
Ataaa & 3764 & 48.2 & 99.8 & PRISM
\end{tabular}

factors. Moreover, ABA response is associated with $\mathrm{Ca}^{2+}$ ion mediated signaling and this motif was reported to be involved in the $\mathrm{Ca}^{2+}$ mediated signaling. Recently, it has been demonstrated that the promoter sequences of $\mathrm{Ca}^{2+}$ ATPases harbors ABA related cis-acting elements (ABRE), indicating ABA mediated $\mathrm{Ca}^{2+}$ ion response (Huda et al., 2013). Taken together, these findings suggest that the $\mathrm{AuCl}_{4}^{-}$response is mediated through ABA signaling, modulating the large set of genes for the adaptation purposes.

We also identified the enriched represented motifs in upstream sequences of downregulated genes, as shown in Supplementary Figure 4. However, these motifs were unknown and not assigned to any important known regulatory element or part of the signal transduction mechanisms.

\section{A HYPOTHETICAL MODEL DISPLAYING AuCl- $\mathbf{4}_{\mathbf{4}}$ SIGNALING}

On the basis of the results obtained in the present work and earlier reported information, a hypothetical model was proposed

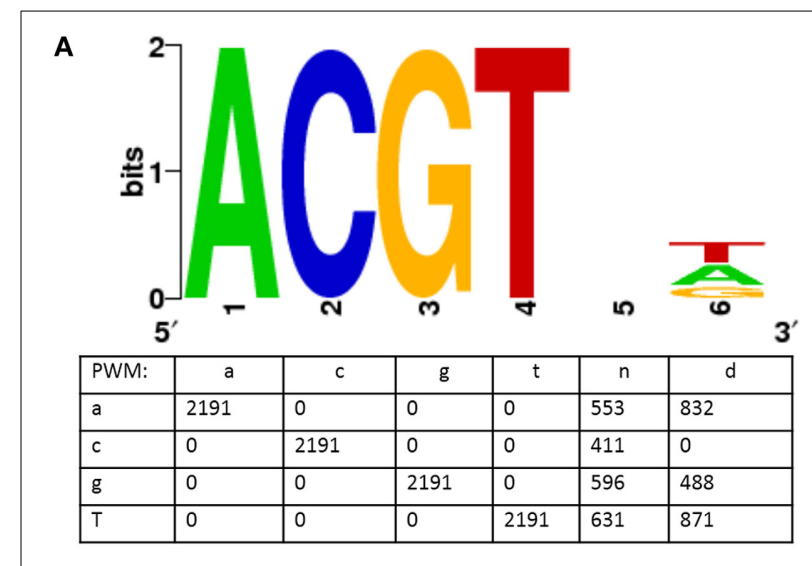

B

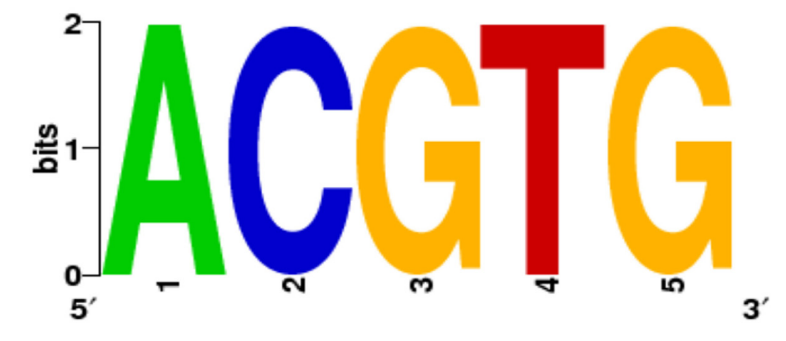

\begin{tabular}{|l|l|l|l|l|l|}
\hline PWN: & \multicolumn{1}{|c|}{ A } & \multicolumn{1}{c|}{ C } & \multicolumn{1}{c|}{ G } & \multicolumn{1}{c|}{ T } & \multicolumn{1}{c|}{ G } \\
\hline A & 656 & 0 & 0 & 0 & 0 \\
\hline C & 0 & 656 & 0 & 0 & 0 \\
\hline G & 0 & 0 & 656 & 0 & 656 \\
\hline T & 0 & 0 & 0 & 656 & 0 \\
\hline
\end{tabular}

FIGURE 6 | ABA Responsive cis-regulatory element (ABRE) identified in upstream region of genes upregulated during $\mathrm{AuCl}_{4}^{-}$treatment. Figure shows two statistically highly significant consensus sequence generated by a motif finder tool, SCOPE (http://genie.dartmouth.edu/ scope/). (A) It shows a motif similar to ABA responsive core element. (B) It shows a motif representing a complete ABA responsive element. The numeric values in the position weight metrix (PWMs) indicates the number of times a particular base present in the respective site. 


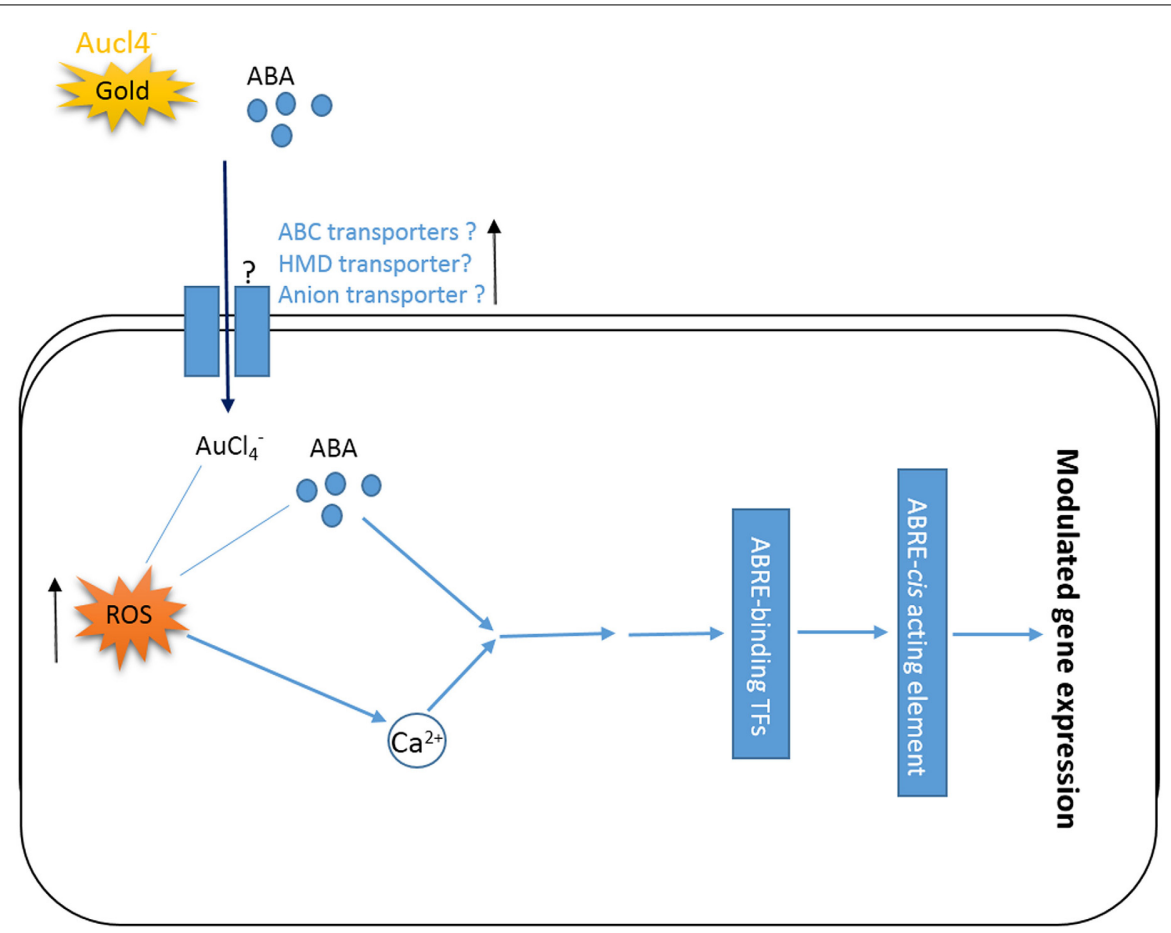

FIGURE 7 | A hypothetical model displaying ABA mediated signaling during gold $\left(\mathrm{AuCl}_{4}^{-}\right)$exposure. $\mathrm{AuCl}_{4}^{-}$could trigger $\mathrm{ABA}$ mediated signaling. $\mathrm{AuCl}_{4}^{-}$and or ABA might be taken inside the cells through various transporters and could elevate the level of ROS triggering the

(Figure 7). This model shows how $\mathrm{AuCl}_{4}^{-}$treatment triggers signals modulating the global gene expression in a short period of time. $\mathrm{AuCl}_{4}^{-}$, like the other heavy metal, may be taken inside the cells through $\mathrm{ABC}$ transporters, heavy metal domain containing transporters and/or anion transporters (Chakrabarty et al., 2009; Socha and Guerinot, 2014). ABC transporters are also known for the ABA influx to the plant cells (Fujii, 2014). Both heavy metal $\left(\mathrm{AuCl}_{4}^{-}\right)$and $\mathrm{ABA}$, potentially could increase the level of ROS (Pottosin et al., 2014) and alter the $\mathrm{Ca}^{2+}$ level inside the cells, inducing ABRE binding transcription factor (Kaplan et al., 2006; Finkler et al., 2007) and eventually regulating the global gene expression by binding on ABRE element (Galon et al., 2010; Huda et al., 2013).

\section{AUTHORS' CONTRIBUTIONS}

Devesh Shukla carried out bioinformatics, analyzed the data and drafted the manuscript. Sneha Krishnamurthy performed the experiments and contributed in data discussion. Shivendra V. Sahi contributed intellectually with all the aspect of this research work and helped in finalizing the manuscript.

\section{ACKNOWLEDGMENTS}

We thank Ms. Donna Wall, Staff Analyst, for her help in carrying out microarray experiment at the University of Kentucky. This research was supported by a grant from The National Science Foundation (Award No. MCB-1158507) to Shivendra V. Sahi. Partial financial support from a WKU-RCAP Category I grant changes in $\mathrm{Ca}^{2+}$ level. Eventually $\mathrm{ABA}$ and/or $\mathrm{Ca}^{2+}$ may induce ABRE-binding transcription factors through some intermediates and regulate the global gene expression. $\uparrow$ Shows the upregulation of related genes.

to Shivendra V. Sahi is also acknowledged. We acknowledge Dr Nilesh Sharma for critically reviewing the manuscript, and the WKU Biotechnology Centre for providing the core facilities to carry out this project.

\section{SUPPLEMENTARY MATERIAL}

The Supplementary Material for this article can be found online at: http://www.frontiersin.org/journal/10.3389/fpls.2014.00652/ abstract

\section{REFERENCES}

Barbez, E., Kubeš, M., Rolč́ík, J., Béziat, C., Pěnčík, A., Wang, B., et al. (2012). A novel putative auxin carrier family regulates intracellular auxin homeostasis in plants. Nature 485, 119-122. doi: 10.1038/nature 11001

Besseau, S., Li, J., and Palva, E. T. (2012). WRKY54 and WRKY70 co-operate as negative regulators of leaf senescence in Arabidopsis thaliana. J. Exp. Bot. 63, 2667-2679. doi: 10.1093/jxb/err450

Cao, M. J., Wang, Z., Wirtz, M., Hell, R., Oliver, D. J., and Xiang, C. B. (2013). SULTR3; is a chloroplast-localized sulfate transporter in Arabidopsis thaliana. Plant J. 73, 607-616. doi: 10.1111/tpj.12059

Chakrabarty, D., Trivedi, P. K., Misra, P., Tiwari, M., Shri, M., Shukla, D., et al. (2009). Comparative transcriptome analysis of arsenate and arsenite stresses in rice seedlings. Chemosphere 74, 688-702. doi: 10.1016/j.chemosphere.2008.09.082

Chen, P. C., Mwakwari, S. C., and Oyelere, A. K. (2008). Gold nanoparticles: from nanomedicine to nanosensing. Nanotechnol. Sci. Appl. 1, 45-66. doi: 10.2147/ NSA.S3707

Christiansen, M. W., and Gregersen, P. L. (2014). Members of the barley NAC transcription factor gene family show differential co-regulation with senescenceassociated genes during senescence of flag leaves. J. Exp. Bot. 65, 4009-4022. doi: $10.1093 / \mathrm{jxb} / \mathrm{eru} 046$ 
Finkler, A., Ashery-Padan, R., and Fromm, H. (2007). CAMTAs: calmodulinbinding transcription activators from plants to human. FEBS Lett. 581, 3893-3898. doi: 10.1016/j.febslet.2007.07.051

Fujii, H. (2014). "Abscisic acid implication in plant growth and stress responses," in Phytohormones: A Window to Metabolism, Signaling and Biotechnological Applications, eds L. S. P. Tran and S. Pal (New York, NY: Springer), 37-54.

Fujiki, Y., Yoshikawa, Y., Sato, T., Inada, N., Ito, M., Nishida, I., et al. (2001). Darkinducible genes from Arabidopsis thaliana are associated with leaf senescence and repressed by sugars. Physiol. Plant 111, 345-352. doi: 10.1034/j.13993054.2001.1110312.x

Galon, Y., Finkler, A., and Fromm, H. (2010). Calcium-regulated transcription in plants. Mol. Plant 3, 653-669. doi: 10.1093/mp/ssq019

Geetha, R., Ashokkumar, T., Tamilselvan, S., Govindaraju, K., Mohamed Sadiq, A., and Singaravelu, G. (2013). Green synthesis of gold nanoparticles and their anticancer activity. Cancer Nanotech. 4, 91-98. doi: 10.1007/s12645-013-0040-9

Hou, B., Lim, E. K., Higgins, G. S., and Bowles, D. J. (2004). N-glucosylation of Cytokinins by glycosyltransferases of Arabidopsis thaliana. J. Biol. Chem. 279, 47822-47832. doi: 10.1074/jbc.M409569200

Huda, K. M. K., Banu, M. S. A., Pathi, K. M., and Tuteja, N. (2013). Reproductive organ and vascular specific promoter of the rice plasma membrane $\mathrm{Ca}^{2+}$ ATPase mediates environmental stress responses in plants. PLoS ONE 8:e57803. doi: 10.1371/journal.pone.0057803

Jain, A., Poling, M. D., Smith, A. P., Nagarajan, V. K., Lahner, B., Meagher, R. B., et al. (2009). Variations in the composition of gelling agents affect morphophysiological and molecular responses to deficiencies of phosphate and other nutrients. Plant Physiol. 150, 1033-1049. doi: 10.1104/pp.109.136184

Jain, A., Sinilal, B., Starnes, D. L., Sanagala, R., Krishnamurthy, S., and Sahi, S. V. (2014). Role of Fe-responsive genes in bioreduction and transport of ionic gold to roots of Arabidopsis thaliana during synthesis of gold nanoparticles. Plant Physiol. Biochem. 84, 189-196. doi: 10.1016/j.plaphy.2014.09.013

Johnston, C. W., Wyatt, M. A., Li, X., Ibrahim, A., Shuster, J., Southam, G., et al. (2013). Gold biomineralization by a metallophore from a gold-associated microbe. Nat. Chem. Biol. 9, 241-243. doi: 10.1038/nchembio.1179

Kang, J., Hwang, J. U., Lee, M., Kim, Y. Y., Assmann, S. M., Martinoia, E., et al. (2010). PDR-type ABC transporter mediates cellular uptake of the phytohormone abscisic acid. Proc. Natl. Acad. Sci. U.S.A. 107, 2355-2360. doi: 10.1073/pnas.0909222107

Kaplan, B., Davydov, O., Knight, H., Galon, Y., Knight, M. R., Fluhr, R., et al. (2006). Rapid transcriptome changes induced by cytosolic $\mathrm{Ca}^{2+}$ transients reveal ABRE-related sequences as $\mathrm{Ca}^{2+}$-responsive cis elements in Arabidopsis. Plant Cell 18, 2733-2748. doi: 10.1105/tpc.106.042713

Kumar, V., and Yadav, S. K. (2009). Plant-mediated synthesis of silver and gold nanoparticles and their applications. J. Chem. Tech. Biotech. 84, 151-157. doi: $10.1002 /$ jctb. 2023

Lee, E. J., Matsumura, Y., Soga, K., Hoson, T., and Koizumi, N. (2007). Glycosyl hydrolases of cell wall are induced by sugar starvation in Arabidopsis. Plant Cell Physiol. 48, 405-413. doi: 10.1093/pcp/pcm009

Lee, M., Lee, K., Lee, J., Noh, E. W., and Lee, Y. (2005). AtPDR12 contributes to lead resistance in Arabidopsis. Plant Physiol. 138, 827-836. doi: 10.1104/pp.104.058107

Li, L., He, Z., Pandey, G. K., Tsuchiya, T., and Luan, S. (2002). Functional cloning and characterization of a plant efflux carrier for multidrug and heavy metal detoxification. J. Biol. Chem. 277, 5360-5368. doi: 10.1074/jbc.M108777200

Limbach, L. K., Wick, P., Manser, P., Grass, R. N., Bruinink, A., and Stark, W. J. (2007). Exposure of engineered nanoparticles to human lung epithelial cells: influence of chemical composition and catalytic activity on oxidative stress. Environ. Sci. Tech. 41, 4158-4163. doi: 10.1021/es062629t

Liu, F., Jiang, H., Ye, S., Chen, W. P., Liang, W., Xu, Y., et al. (2010). The Arabidopsis $\mathrm{P} 450$ protein CYP82C2 modulates jasmonate-induced root growth inhibition, defense gene expression and indole glucosinolate biosynthesis. Cell Res. 20, 539-552. doi: 10.1038/cr.2010.36

Livak, K. J., and Schmittgen, T. D. (2001). Analysis of relative gene expression data using real-time quantitative PCR and the 2 (-Delta Delta C(T) methods. Methods 25, 402-408. doi: 10.1006/meth.2001.1262

Mars, K. A. (1996). The functions and regulation of glutathione-S-transferases in plants. Annu. Rev. Plant Physiol. Plant Mol. Biol. 47, 127-158. doi: 10.1146/annurev.arplant.47.1.127

Mishra, M., Kanwar, P., Singh, A., Pandey, A., Kapoor, S., and Pandey, G. K. (2013). Plant omics: genome-wide analysis of ABA Repressor1 (ABR1) related genes in rice during abiotic stress and development. Omics J. Int. Biol. 17, 439-450. doi: 10.1089/omi.2012.0074

Mishra, S., Shukla, A., Upadhyay, S., Sharma, P., Singh, S., Phukan, U. J., et al. (2014). Identification, occurrence, and validation of DRE and ABRE cisregulatory motifs in the promoter regions of genes of Arabidopsis thaliana. J. Int. Plant Biol. 56, 388-399. doi: 10.1111/jipb.12149

Niemietz, C. M., and Tyerman, S. D. (2002). New potent inhibitors of aquaporins: silver and gold compounds inhibit aquaporins of plant and human origin. FEBS. Let. 531, 443-447. doi: 10.1016/S0014-5793(02)03581-0

Nitta, Y., Ding, P., and Zhang, Y. (in press). Heterotrimeric G proteins in plant defense against pathogens and aba signaling. Environ. Exp. Bot. doi: 10.1016/j. envexpbot.2014.06.011

Pandey, G. K., Grant, J. J., Cheong, Y. H., Kim, B. G., Li, L., and Luan, S. (2005). ABR1, an APETALA2-domain transcription factor that functions as a repressor of ABA response in Arabidopsis. Plant Physiol. 139, 1185-1193. doi: 10.1104/pp.105.066324

Pottosin, I., Velarde-Buendía, A. M., Bose, J., Zepeda-Jazo, I., Shabala, S., and Dobrovinskaya, O. (2014). Cross-talk between reactive oxygen species and polyamines in regulation of ion transport across the plasma membrane: implications for plant adaptive responses. J. Exp. Bot. 65, 1271-1283. doi: $10.1093 /$ jxb/ert423

Reith, F., Etschmann, B., Grosse, C., Moors, H., Benotmane, M. A., Monsieurs, P., et al. (2009). Mechanisms of gold biomineralization in the bacterium Cupriavidus metallidurans. Proc. Natl. Acad. Sci. U.S.A. 106, 17757-17762. doi: 10.1073/pnas.0904583106

Ren, X., Chen, Z., Liu, Y., Zhang, H., Zhang, M., Liu, Q., et al. (2010). ABO3, a WRKY transcription factor, mediates plant responses to abscisic acid and drought tolerance in Arabidopsis. Plant J. 63, 417-429. doi: 10.1111/j.1365313X.2010.04248.x

Rodriguez, E., Parsons, J. G., Peralta-Videa, J. R., Cruz-Jimenez, G., RomeroGonzalez, J., Sanchez-Salcido, B. E., et al. (2007). Potential of Chilopsis linearis for gold phytomining: using XAS to determine gold reduction and nanoparticle formation within plant tissues. Int. J. Phyto. 9, 133-147. doi: 10.1080/15226510701232807

Schluttenhofer, C., Pattanaik, S., Patra, B., and Yuan, L. (2014). Analyses of Catharanthus roseus and Arabidopsis thaliana WRKY transcription factors reveal involvement in jasmonate signaling. BMC Genomics 15:502. doi: 10.1186/1471-2164-15-502

Sharma, N. C., Sahi, S. V., Nath, S., Parsons, J. G., Gardea-Torresdey, J. L., and Pal, T. (2007). Synthesis of plant-mediated gold nanoparticles and catalytic role of biomatrix-embedded nanomaterials. Environ. Sci. Tech. 41, 5137-5142. doi: 10.1021/es062929a

Shibuya, K., Shimizu, K., Niki, T., and Ichimura, K. (2014). Identification of NAC transcription factor, EPHEMERAL1, that controls petal senescence in Japanese morning glory. Plant J. Cell Mol. Biol. 79, 1044-1051. doi: 10.1111/tpj.12605

Shukla, D., Kesari, R., Mishra, S., Dwivedi, S., Tripathi, R. D., Nath, P., et al. (2012). Expression of phytochelatin synthase from aquatic macrophyte Ceratophyllum demersum L. enhances cadmium and arsenic accumulation in tobacco. Plant Cell Rep. 31, 1687-1699. doi: 10.1007/s00299-012-1283-3

Shukla, D., Kesari, R., Tiwari, M., Dwivedi, S., Tripathi, R. D., Nath, P., et al. (2013b). Expression of Ceratophyllum demersum phytochelatin synthase, CdPCS1, in Escherichia coli and Arabidopsis enhances heavy metal(loid)s accumulation. Protoplasma 250, 1263-1272. doi: 10.1007/s00709-0130508-9

Shukla, D., Tiwari, M., Tripathi, R. D., Nath, P., and Trivedi, P. K. (2013a). Synthetic phytochelatins complement a phytochelatin-deficient Arabidopsis mutant and enhance the accumulation of heavy metal(loid)s. Biochem. Biophy. Res. Comm. 434, 664-669. doi: 10.1016/j.bbrc.2013.03.138

Socha, A. L., and Guerinot, M. L. (2014). Mn-euvering manganese: the role of transporter gene family members in manganese uptake and mobilization in plants. Front. Plant Sci. 5:106. doi: 10.3389/fpls.2014.00106

Spivak, M. Y., Bubnov, R. V., Yemets, I. M., Lazarenko, L. M., Tymoshok, N. O., and Ulberg, Z. R. (2013). Development and testing of gold nanoparticles for drug delivery and treatment of heart failure: a theranostic potential for PPP cardiology. EPMA. J. 4:20. doi: 10.1186/1878-5085-4-20

Starnes, D. L., Jain, A., and Sahi, S. V. (2010). In planta engineering of gold nanoparticles of desirable geometries by modulating growth conditions: an environment-friendly approach. Environ. Sci. Tech. 44, 7110-7115. doi: $10.1021 /$ es101136q 
Takase, T., Nakazawa, M., Ishikawa, A., Manabe, K., and Matsui, M. (2003). DLF 2, a new member of the Arabidopsis GH3 gene family, is involved in red light-specific hypocotyl elongation. Plant Cell Physiol. 44, 1071-1080. doi: $10.1093 / \mathrm{pcp} / \mathrm{pcg} 130$

Taylor, A. F., Rylott, E. L., Anderson, C. W., and Bruce, N. C. (2014). Investigating the toxicity, uptake, Nanoparticle formation and genetic response of plants to gold. PLoS ONE 9:e93793. doi: 10.1371/journal.pone.0093793

Tian, L., Musetti, V., Kim, J., Magallanes-Lundback, M., and DellaPenna, D. (2004). the Arabidopsis LUT1 locus encodes a member of the cytochrome p450 family that is required for carotenoid epsilon-ring hydroxylation activity. Proc. Natl. Acad. Sci. U.S.A. 101, 402-407. doi: 10.1073/pnas.2237237100

Tiwari, M., Sharma, D., Singh, M., Tripathi, R. D., and Trivedi, P. K. (2014). Expression of OsMATE1 and OsMATE2 alters development, stress responses and pathogen susceptibility in Arabidopsis. Sci. Rep. 4:3964. doi: 10.1038/srep03964

Tripathi, P., Rabara, R. C., and Rushton, P. J. (2014). A systems biology perspective on the role of WRKY transcription factors in drought responses in plants. Planta 239, 255-266. doi: 10.1007/s00425-013-1985-y

Wagner, U., Edwards, R., Dixon, D. P., and Mauch, F. (2002). Probing the diversity of the Arabidopsis glutathione S-transferase gene family. Plant Mol. Biol. 49, 515-532. doi: 10.1023/A:1015557300450

Winkel-Shirley, B. (2002). Biosynthesis of flavonoids and effects of stress. Curr. Opin. Plant Biol. 5, 218-223. doi: 10.1016/S1369-5266(02) 00256-X

Yadav, D. K., Shukla, D., and Tuteja, N. (2013). Rice heterotrimeric G-protein alpha subunit (RGA1): in silico analysis of the gene and promoter and its upregulation under abiotic stress. Plant Physiol. Biochem. 63, 262-271. doi: 10.1016/j.plaphy.2012.11.031

Yadav, D. K., Shukla, D., and Tuteja, N. (2014). Isolation, in silico characterization, localization and expression analysis of abiotic stress-responsive rice G-protein beta subunit (RGB1). Plant Sig. Behav. 9:e28890. doi: 10.4161/psb.28890

Yeh, Y. C., Creran, B., and Rotello, V. M. (2012). Gold nanoparticles: preparation, properties, and applications in bionanotechnology. Nanoscale 4, 1871-1880. doi: $10.1039 / \mathrm{cln} 11188 \mathrm{~d}$

Conflict of Interest Statement: The authors declare that the research was conducted in the absence of any commercial or financial relationships that could be construed as a potential conflict of interest.

Received: 13 August 2014; accepted: 03 November 2014; published online: 28 November 2014.

Citation: Shukla D, Krishnamurthy S and Sahi SV (2014) Genome wide transcriptome analysis reveals $A B A$ mediated response in Arabidopsis during gold $\left(\mathrm{AuCl}_{4}^{-}\right)$ treatment. Front. Plant Sci. 5:652. doi: 10.3389/fpls.2014.00652

This article was submitted to Plant Genetics and Genomics, a section of the journal Frontiers in Plant Science.

Copyright (c) 2014 Shukla, Krishnamurthy and Sahi. This is an open-access article distributed under the terms of the Creative Commons Attribution License (CC BY). The use, distribution or reproduction in other forums is permitted, provided the original author(s) or licensor are credited and that the original publication in this journal is cited, in accordance with accepted academic practice. No use, distribution or reproduction is permitted which does not comply with these terms. 